\title{
IMPLEMENTACIÓN SEMIPROFESIONAL DE CIRCUITOS IMPRESOS I
}

\section{PRINTED CIRCUIT SEMI IMPLEMENTATION I}

Arturo Pérez París: Universidad de Alcalá de Henares. Madrid (España) arturo.perez@mixmail.com

\section{CURRÍCULUM VITAE DE CADA AUTOR}

Escuela Politécnica de la Universidad de Alcalá de Henares. Ingeniero electrónico y literato. Destacan sus estudios sobre aplicaciones eléctricas y motricidad sobre los que ha publicado varios artículos científicos.

\section{RESUMEN}

La implementación semiprofesional de circuitos impresos permite la construcción de sus propios equipos y aplicaciones electrónicas. Por ello, este artículo va destinado principalmente a los estudiantes de ingenierías y bachilleratos técnicos. En él podrás seguir, paso a paso, la elaboración de estos circuitos con figuras explicativas en imágenes que reflejan con claridad la explicación dada por el texto, en la que además encontrarás variados consejos. La génesis de este artículo es parte del proyecto final de carrera de su autor, "Control digital de una montura ecuatorial para microcámaras".

\section{PALABRAS CLAVE}

Circuitos impresos - Aplicaciones electrónicas - Estudiantes 


\begin{abstract}
Implementation semi printed circuit allows the construction of their own equipment and electronic applications. Therefore, this article is intended mainly for students of engineering and technical high schools. There you can follow step by step, the development of these circuits with explanatory figures in images that clearly reflect the explanation given by the text, which will also find various tips. The genesis of this paper is part of the final thesis of the author, "Digital control of an equatorial mount for micro cameras."
\end{abstract}

\title{
KEY WORDS
}

Printed circuit boards - Electronic Applications - Students

\section{TEXTO:}

El presente artículo pretende introducir al lector, a la manera de recetario de cocina, en la implementación semiprofesional de circuitos impresos, con la finalidad de facilitarle la construcción de sus propios equipos y aplicaciones electrónicas. Está orientado fundamentalmente a los estudiantes de ingenierías (Industriales, Telecomunicaciones, etc.) y bachilleratos técnicos (antiguas F.P.) que precisen de ello. Lo dividiré en tres partes debido a su extensión, no obstante ser una mera introducción a estas técnicas. En esta primera serán relacionados los cinco primeros pasos a dar.

El método semiprofesional es aquel que permite la implementación de prototipos, con una calidad media - baja de clase 1, ya que no permite la construcción de PCBs con taladro metalizado y no da para emplear técnicas de multicapa. El método como tal vendrá a ser como sigue: 
$1^{\circ}$.- Se realizará el diseño general del sistema (a implementar) con el programa de CAE más adecuado (aquí se empleó TANGO por ser el paquete cuyo uso mejor se conocía) y utilizando los métodos que se tienen al alcance para ello (ordenadores, impresoras, etc.):

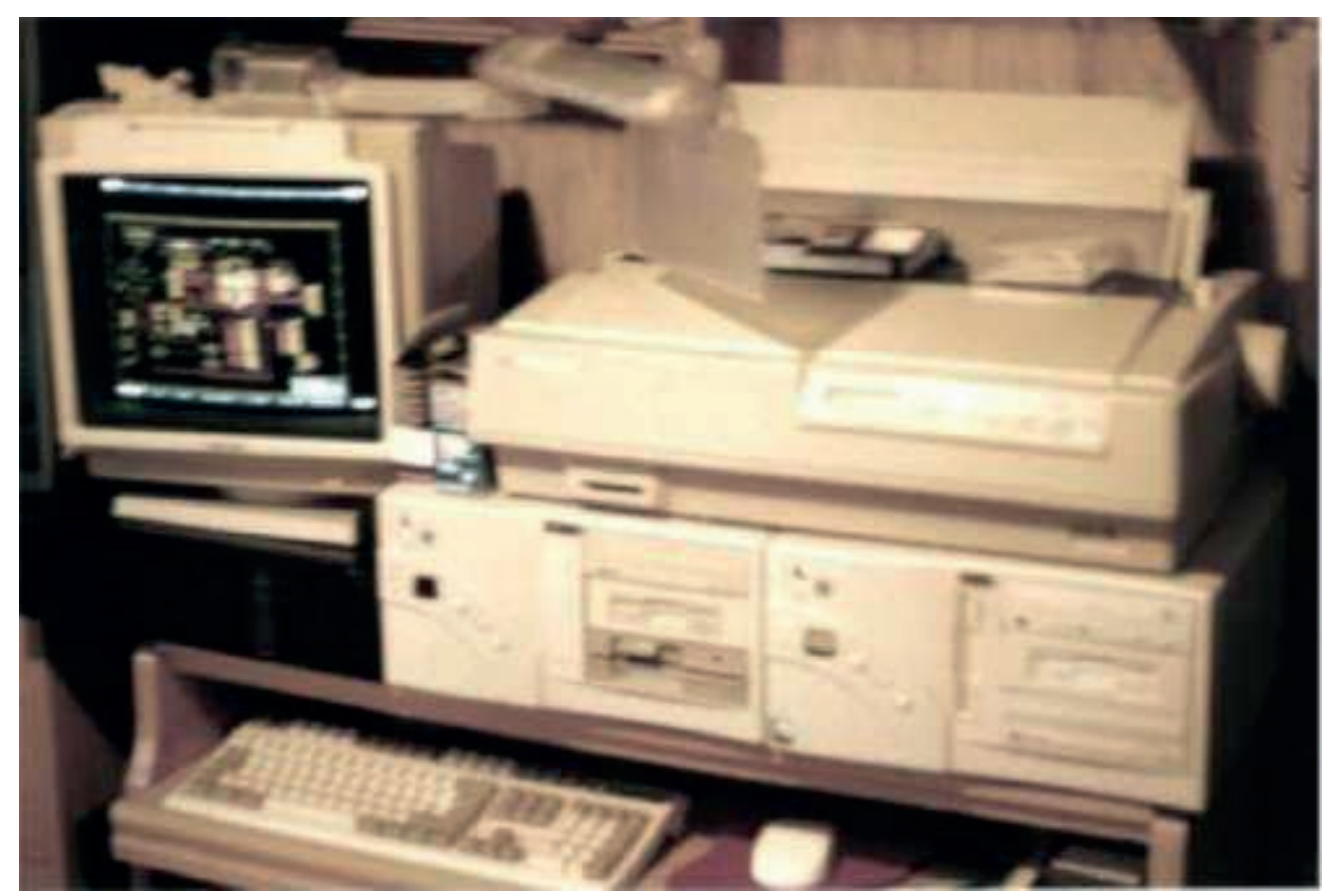

Fig. 1

Seguidamente se pasará a la creación de la placa. Primero se situarán los componentes de la manera más adecuada sobre la superficie definida que se le proporcione al programa, guiándonos por los vectores de ubicación que nos marque la mejor colocación de los componentes, tal y como se muestra en la Fig. 2: 


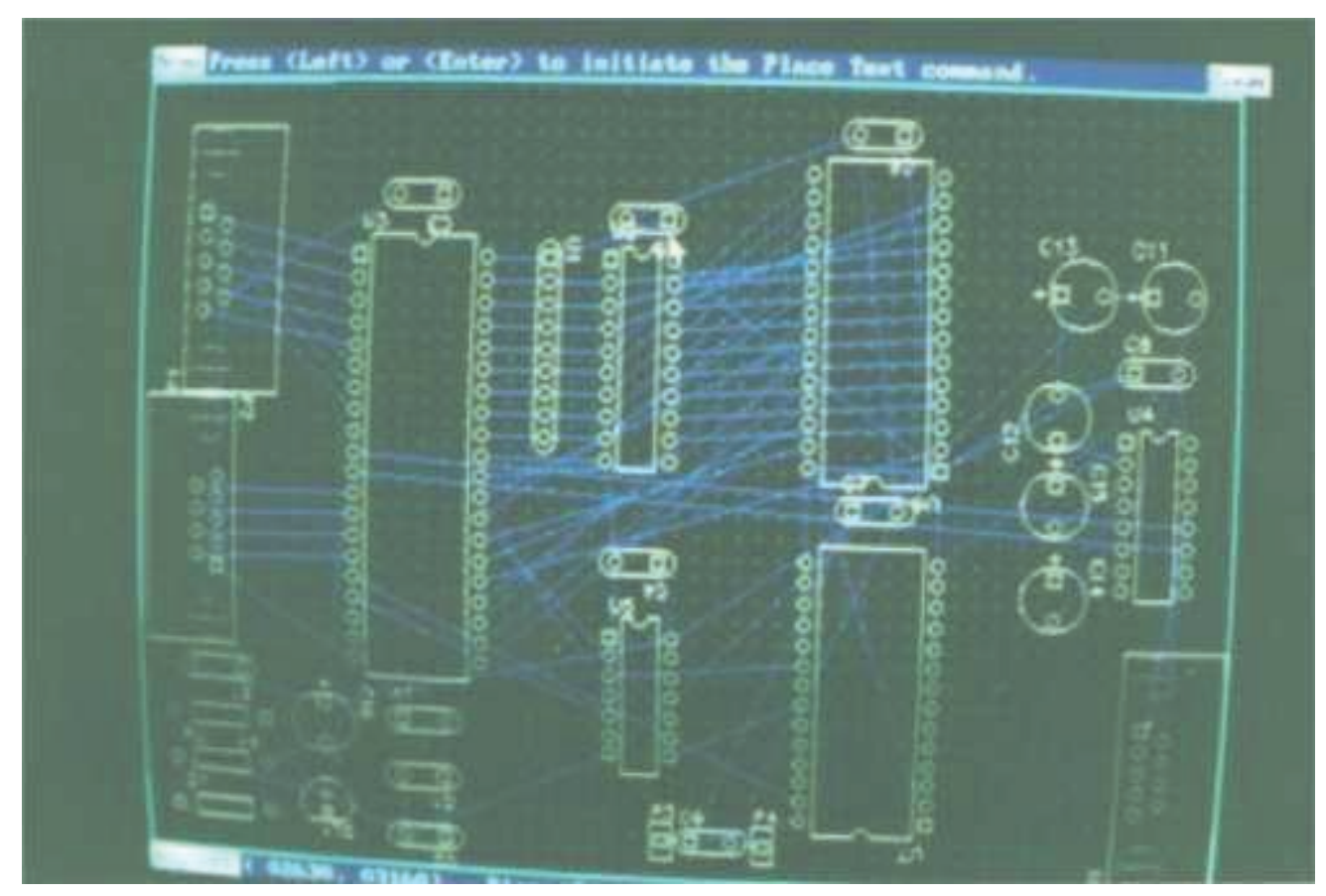

Fig. 2

Después se procederá al trazado de las pistas o "ruteado", lo cual será realizado de manera automática por el propio ordenador a través del programa y los archivos de datos adecuados. A partir de este trabajo se retocará a conveniencia, dando como resultado: 


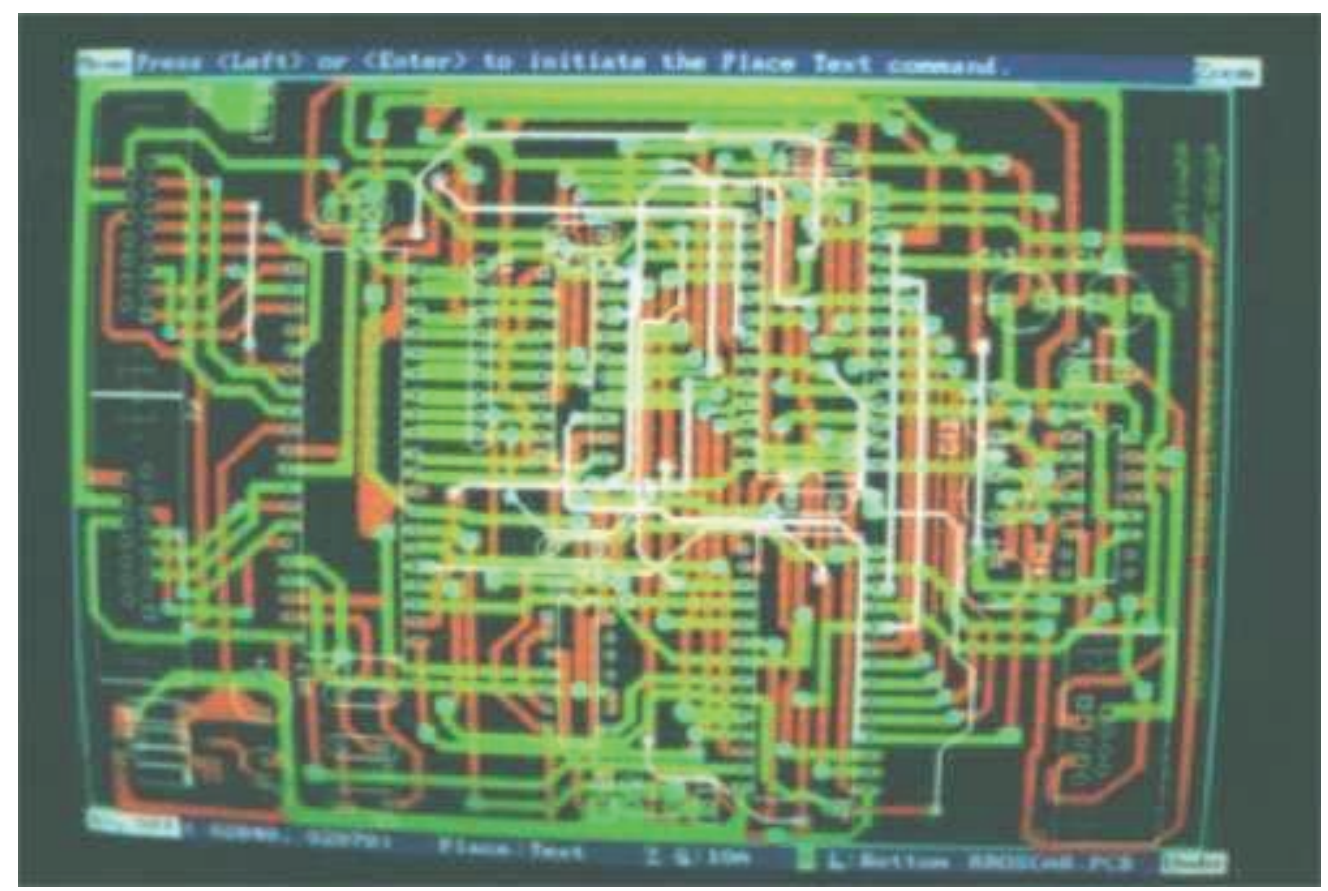

Fig. 3

Esta imagen muestra el conjunto de pistas de las dos caras y el serigrafiado de los componentes, que sería el diseño de PCB perseguido para la aplicación.

$2^{\circ}$.- A continuación obtendremos las máscaras de diseño. Las impresiones de éstas se harán con impresoras láser o, en su defecto, de inyección de tinta sobre papel vegetal o, mejor aún, de poliéster, a ser posible, de $75 \mathrm{~mm}$ de espesor. Ambos tienen una transparencia media, buena estabilidad térmica (no se deterioran con el calor en el proceso de insolado), buena adherencia a la tinta y por supuesto un coste económico razonable. Quizás de los dos tipos de papel relacionados, él más adecuado sea el segundo, por ser el más transparente y tener mayor estabilidad térmica que el primero. Al generar los "fotolitos", se pintarán los "pads" con su agujero y corona, es decir, no rellenos, con el fin de facilitar el taladrado en una etapa posterior, evitando en lo posible excentricidades de los agujeros y el posible deterioro en los "pads" de la cara opuesta (placas doble cara). 
$3^{\circ}$.- Seguidamente se pasará a cortar a medida las placas. El útil que se empleó aquí fue:

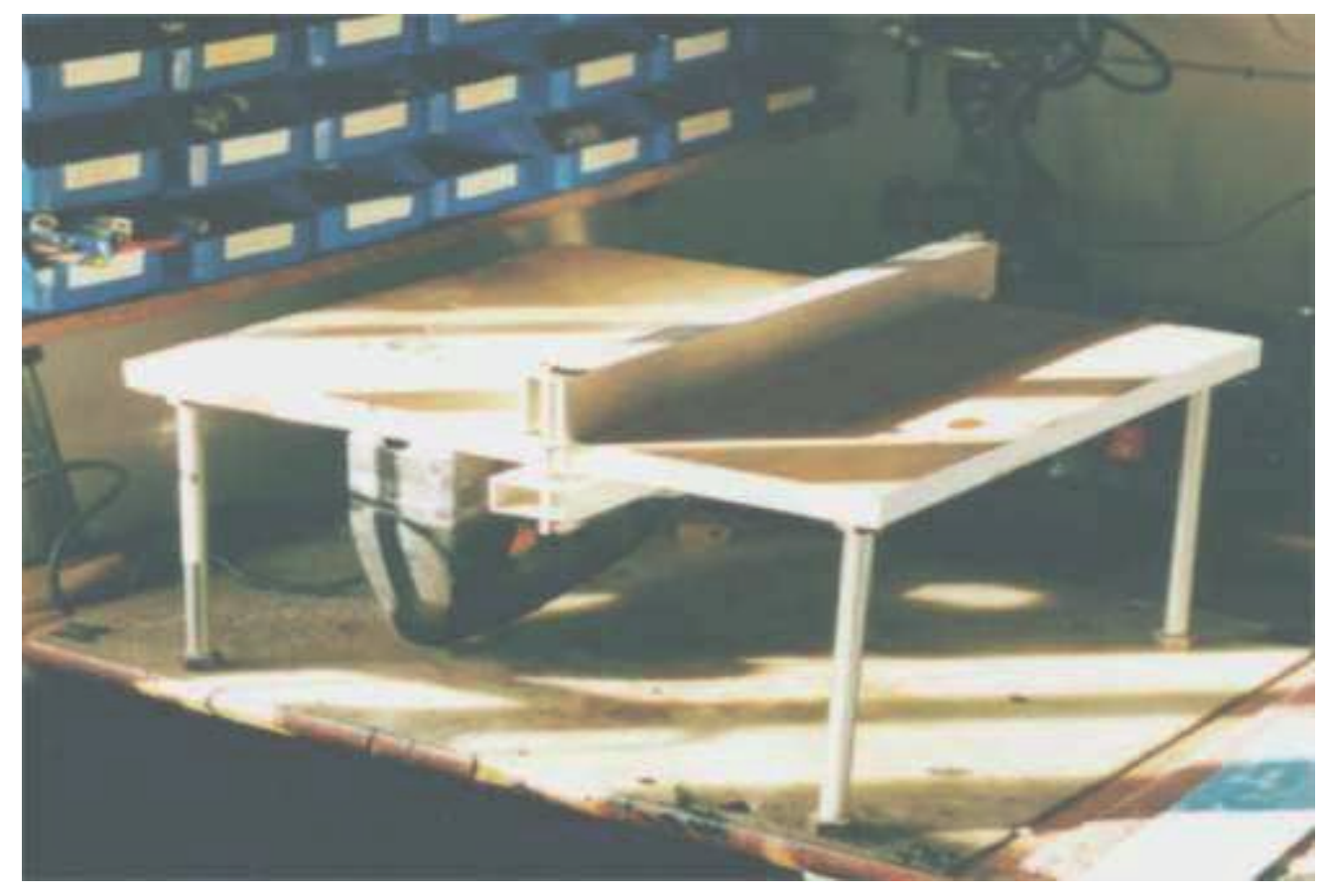

Fig. $4 a$

Obteniendo los resultados mostrados a continuación: 


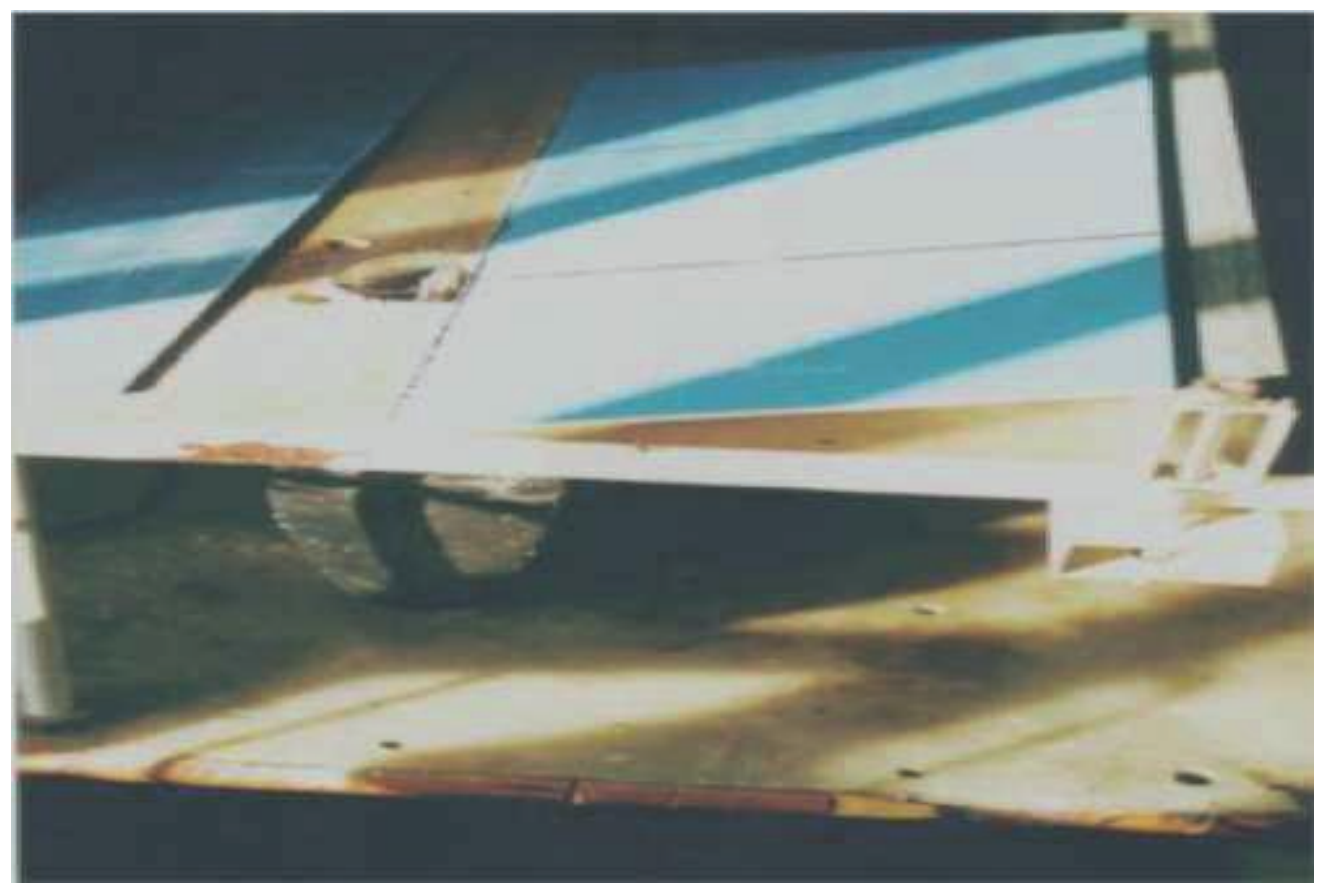

Fig. $4 b$

Estas placas vienen presensibilizadas con un barniz fotosensible positivo de fábrica, para obtener óptimos resultados en los procesos químicos posteriores. El siguiente paso será proceder al marcado de los agujeros de referencia:

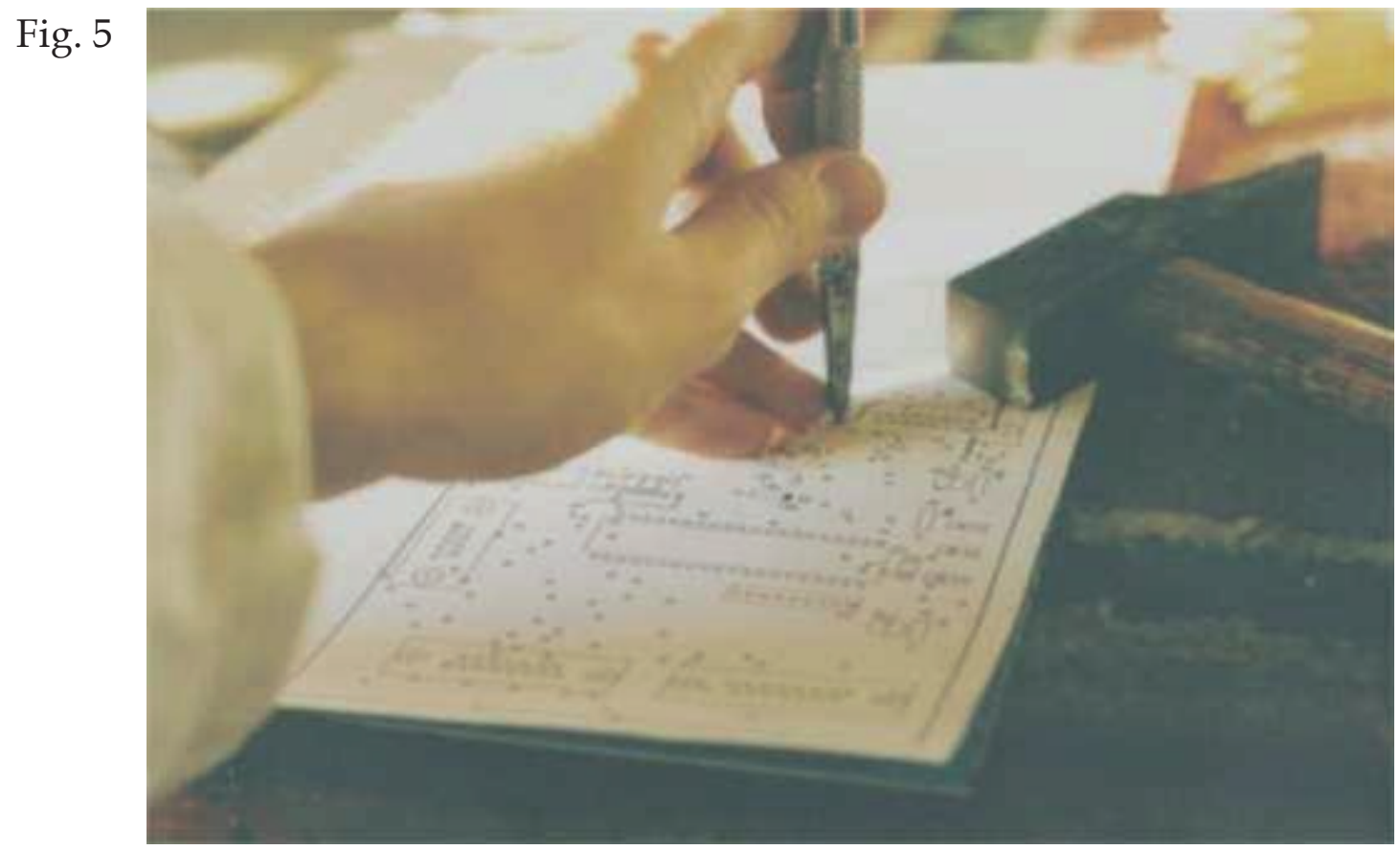


A continuación, se procede al taladrado, tal y como se muestra en la Fig. 6. Estas maniobras nos servirán para centrar las pistas correctamente en las dos caras de la placa, consiguiendo así la correcta coincidencia entre pistas, "pads" (nodos de conexión del componente con las pistas) y vías (pasos de conexión entre pistas de diferentes caras).

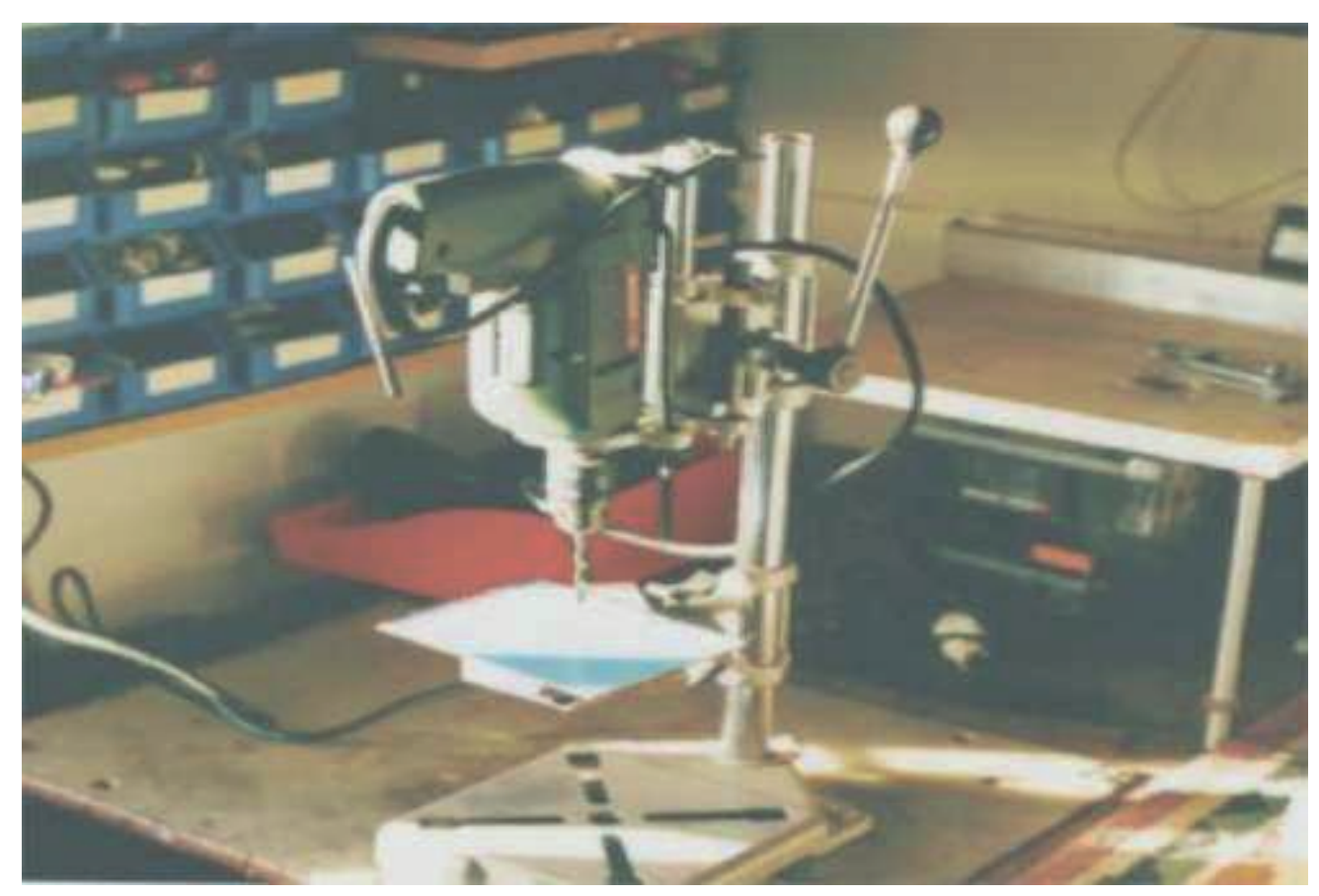

Fig. 6

$4^{\circ}$.- El siguiente paso será el insolado de la placa, que consiste en la degeneración del barniz fotosensible mediante radiación electromagnética ultravioleta, con el fin de "pintar" las pistas del circuito que se van a implementar en función de las máscaras. Éstas se colocarán centradas con los agujeros guía antes realizados sobre la placa, a la que previamente se le habrá despojado del plástico protector de fábrica: 


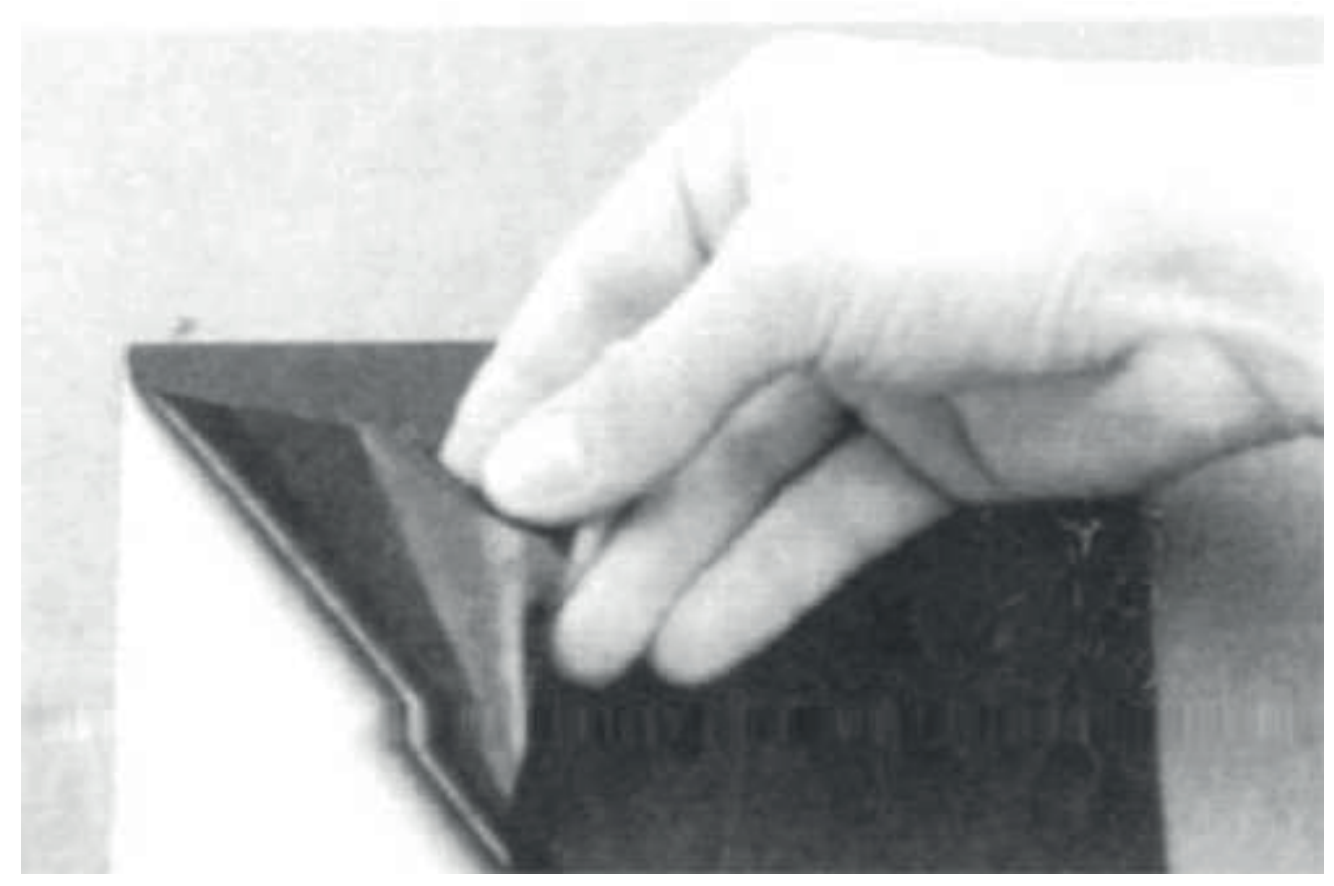

Fig. 7

Dicho posicionado se hará de manera que habrán de estar en contacto las caras que contengan la emulsión (en la máscara la tinta y en la placa el barniz) para que la transferencia del motivo sea lo más eficiente posible, evitando los deterioros laterales de las pistas en el proceso de atacado por una insuficiencia de definición de los contornos (etching). La duración de este proceso variará en función de la fuente lumínica empleada. Así, a luz solar bastará con una exposición de 7 a 10 minutos, con luz actínica de 4 a 7 minutos y con luz fluorescente, será suficiente de 5 a 7 minutos. Detalle de lo que sería una máquina para insolar placas se recoge en la siguiente fotografía: 


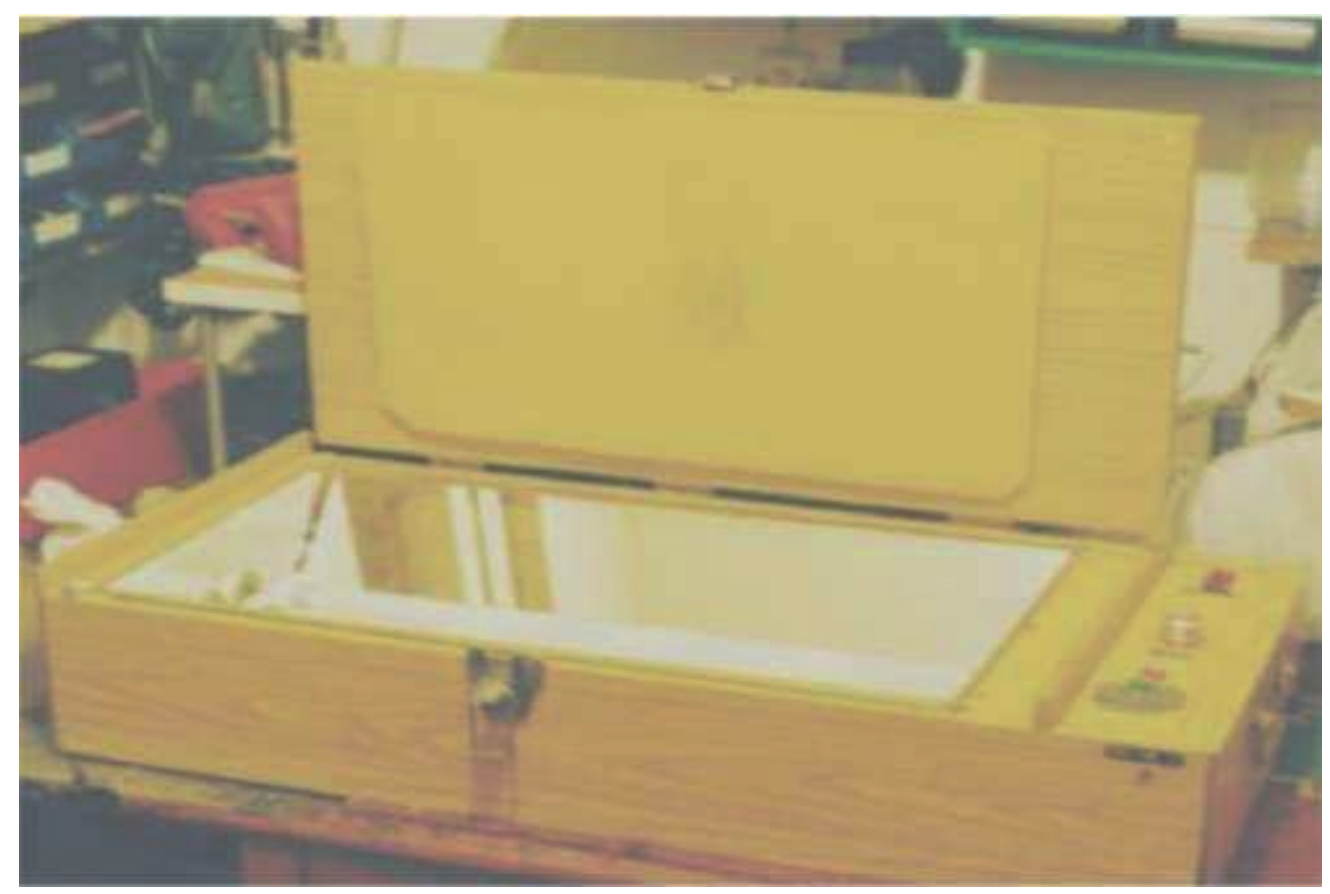

Fig. 8

Hasta aquí la primera entrega. Les espero en la próxima, donde continuaremos con la relación de pasos para implementar nuestras propias placas de circuito impreso. Añadir que la génesis de este artículo es parte de mi proyecto final de carrera "Control digital de una montura ecuatorial para microcámaras" en el Dpto. de Teoría de la Comunicación de la Escuela Politécnica de la Universidad de Alcalá. 